\title{
Karyotype structure and chromosome fragility in the grass Phleum echinatum Host
}

\author{
Aleksandra Grabowska-Joachimiak • Adam Kula • \\ Dorota Gernand-Kliefoth • Andrzej J. Joachimiak
}

Received: 5 June 2014 / Accepted: 14 July 2014 / Published online: 24 July 2014

(C) The Author(s) 2014. This article is published with open access at Springerlink.com

\begin{abstract}
Phleum echinatum Host $(2 n=2 x=10)$ is an annual Mediterranean species which differs from other representatives of the genus Phleum by reduced chromosome number, asymmetric karyotype and unusually high amount of DNA in the genome. Chromosomes of this plant were studied using conventional acetic-orcein staining and fluorescence in situ hybridization (FISH). FISH showed the major 35S ribosomal DNA (rDNA) site at the secondary constriction of satellite chromosome (3) and the minor 35S rDNA site near 5S rDNA cluster in the monobrachial chromosome 5 . Telomeric repeats were detected at all chromosome ends within secondary constriction in satellited chromosome 3 and at the centromeric regions of chromosomes 1 and 2. Intrachromosomally located telomeric repeats are probably traces of chromosomal rearrangements that have shaped $P$. echinatum genome; they were prone to breakage which was manifested in chromosome fragmentation. The most distinct telomeric signals, suggesting massive amplification of interstitial telomeric sequences (ITRs), were observed at the nucleolar organizer region (NOR) of the third chromosome pair. Double FISH confirmed co-localization of telomeric and $35 \mathrm{~S}$ rDNA repeats in this
\end{abstract}

Handling Editor: Peter Nick

Electronic supplementary material The online version of this article (doi:10.1007/s00709-014-0681-5) contains supplementary material, which is available to authorized users.

A. Grabowska-Joachimiak $(\bowtie) \cdot$ A. Kula

Department of Plant Breeding and Seed Science, University

of Agriculture in Cracow, Łobzowska 24, Cracow 31-140, Poland

e-mail: rrjoachi@cyf-kr.edu.pl

D. Gernand-Kliefoth

Leibniz-Institute of Plant Genetics and Crop Plant Research (IPK),

Gatersleben 06466, Germany

A. J. Joachimiak

Department of Plant Cytology and Embryology, Institute of Botany,

Jagiellonian University, Gronostajowa 9, Cracow 30-387, Poland locus characterized by the biggest fragility in the karyotype. Fragile sites of $P$. echinatum, composed of amplified telomeric repeats, may bear a resemblance to metazoan rare fragile sites enriched in microsatellite repeats.

Keywords Phleum echinatum · Fragile sites · FISH · rDNA · Interstitial telomeric sequences $\cdot$ Chromosome fusions

\section{Introduction}

Phleum echinatum Host is an annual Mediterranean species of timothy belonging to the section Phleum. Its somatic chromosome number $2 n=2 x=10$, established by Ellestrom and Tijo in 1950, was confirmed after 55 years (Kula 2005). The basic chromosome number $x=5$ in P. echinatum differs from the number $x=7$ occurring in all other representatives of the genus Phleum (Joachimiak and Kula 1993, 1996; Joachimiak 2005; Stewart et al. 2009). Moreover, the species shows some other untypical features-it is characterized by distinct intrachromosomal asymmetry of the karyotype, much bigger chromosomes and a higher DNA content in the genome $(\mathrm{Cx}=$ $3.64 \mathrm{pg}$ vs. $\mathrm{Cx}=1.34-1.69 \mathrm{pg}$ in other species) (Sliwinska et al. 2003; Joachimiak 2005; Kula 2005). All these observations suggest that $P$. echinatum shows a derived, highly differentiated genome, which was shaped as a result of dysploid reduction and increase in genomic DNA amount.

Kula (2005) noted that the majority of the metaphase plates of $P$. echinatum which were observed contained fragments of chromosomes. Significantly, such chromosome fragmentation was not observed in any of other Phleum species analyzed by him. It could suggest that in $P$. echinatum karyotype, fragile sites may occur. Fragile sites are manifested as non-random breaks and gaps on metaphase chromosomes (Casper et al. 2002). So far, chromosome lesions caused by the occurrence of such points in chromosomes have been most frequently 
observed in animals. Various ranges of this phenomenon were described in, e.g. insects, rodents and primates (Toledo et al. 2000; Ruiz-Herrera et al. 2002). In humans, fragile sites in autosomes are frequently involved in chromosomal rearrangements in cancer cells (Hellman et al. 2002), whereas fragility of the $\mathrm{X}$ chromosome is responsible for the most common familial form of mental retardation (Kaufmann and Reiss 1999). In plants, non-random chromosome breaks are definitely less frequent and almost exclusively restricted to interstitial 35S ribosomal DNA (rDNA) sites, and this phenomenon was analyzed in more detail in Lolium (Huang et al. 2008, 2009).

More precise studies of $P$. echinatum concerning location of repetitive sequences (rDNA, telomeric sequences) have not been performed yet. Because of reduced chromosome number, much attention should be paid to possible traces of chromosomal rearrangements in this species. Moreover, it should be explained whether observed chromosome fragmentation is accidental or the breaks occur in some particular sites. Our main objectives were (i) to localize chromosome breaks; (ii) to show the location of chromosomal sites of 5S rDNA, 35S rDNA, and telomeric sequences; and (iii) to analyze the P. echinatum karyotype and its chromosome fragile sites more precisely.

\section{Materials and methods}

\section{Plant material}

The plant material was collected from a natural stand in Sicily and delivered by the Botanical Garden in Bydgoszcz, Poland. In both cases, it came from the area between the town of Ficuzza and the Rocca Busambra foothills (1,613 m.a.s.1.) situated in the north-west of Sicily. For comparison, during identification of the material, original herbarium cards of P. echinatum Host from the Botanical Garden of Palermo were used.

\section{Chromosome preparations}

The chromosome preparations were obtained from root-tip meristems of 20 specimens. Excised root tips were incubated in 8-hydroxyquinoline for $4 \mathrm{~h}$ at room temperature, rinsed in distilled water and fixed in absolute ethanol/glacial acetic acid (3:1) for $24 \mathrm{~h}$. Then, the material was stained with $2 \%$ aceticorcein according to Marciniuk et al. (2012) or softened and prepared for fluorescence in situ hybridization (FISH) according to Gernand et al. (2007). Chromosome lengths were calculated on the basis of measurements performed on digitally captured chromosomes (NIS-elements software, Nikon).
DNA probes and fluorescence in situ hybridization

The Arabidopsis thaliana-derived clone pCT4.2 (Campell et al. 1992) and BAC clone (EMBL accession no. AF167571) were used as 5S and 35S rDNA probes, respectively. An Arabidopsis-type telomere probe was generated by PCR amplification according to Ijdo et al. (1991).

In situ hybridization sequences were labeled by nick translation or PCR with digoxigenin-11-dUTP or biotin-16-dUTP. FISH on the squashed root tips was performed as described by Houben et al. (2001). Briefly, 20 ng of each probe was applied per slide. Hybridization sites of digoxigenated and biotinylated probes were immunodetected either by rhodamineconjugated anti-digoxigenin sheep antibodies and rhodamine anti-sheep antibody for signal amplification or Alexa488conjugated streptavidin and FITC-conjugated antistreptavidin antibodies, respectively. FISH preparations were mounted and counterstained in Vectashield (Vector Laboratories), containing $2 \mu \mathrm{g} / \mathrm{ml}$ of DAPI. Epifluorescence signals were recorded electronically with a cooled chargecoupled device camera (ORCA-ER Hamamatsu). The image superimposition was performed with Adobe Photoshop 6.0.

\section{Results}

Chromosome number and morphology

Among the 69 conventionally stained metaphase plates, only three plates had 10 unfragmented chromosomes (Fig. 1a). In the other plates, 11 to 16 chromosomes and their fragments were found (see supplementary material). Having accepted the karyotype structure presented by Ellestrom and Tijo (1950), an interpretation of particular metaphases with chromosome breaks was possible (Fig. 1b-d). P. echinatum karyotype contained two pairs of long metacentrics (8.93 and $7.22 \mu \mathrm{m}$ ), a pair of submetacentric satellited (SAT) chromosomes $(6.72 \mu \mathrm{m})$, one pair of medium-sized subtelocentric chromosomes $(5.58 \mu \mathrm{m})$ and one pair of the smallest in the karyotype telocentric chromosomes $(4.18 \mu \mathrm{m})$ (Fig. 1e).

Detailed analysis of the metaphase plates with fragmented chromosomes revealed the presence of three fragile sites in the karyotype of $P$. echinatum. They were the secondary constriction of SAT chromosome (3) and the primary constrictions in the two longest chromosomes (1 and 2) (Fig. 1e). In only one of the analyzed metaphase plates, a chromosome lesion was observed in a different locus (lesion at centromere of chromosome 4).

FISH mapping of rDNA and telomeric repeats

In all the preparations, two solid 35S rDNA signals were observed within satellite chromosomes (3), whereas $5 \mathrm{~S}$ 


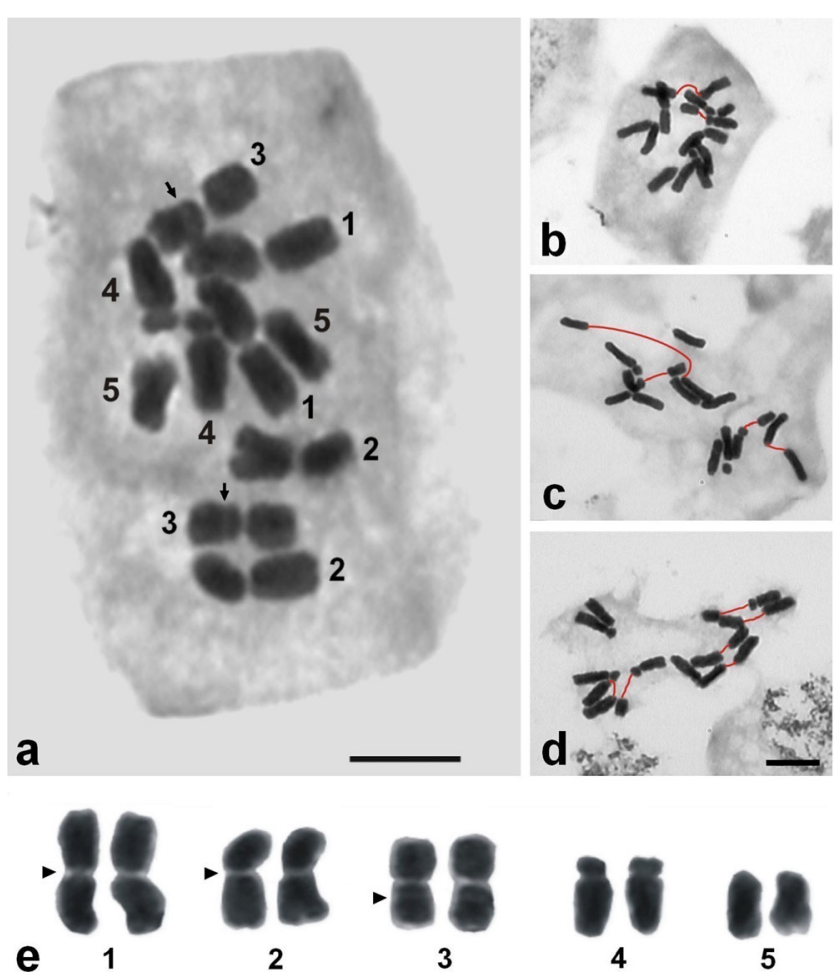

Fig. 1 Chromosomes of Phleum echinatum. a Complete metaphase plate with 10 unfragmented chromosomes. Arrows point to the secondary constriction of satellite chromosomes (3). b-d Metaphase plates with chromosome breaks (red). e Conventional karyotype $(2 n=10)$. Arrowheads point to the fragile sites. Bar, $5 \mu \mathrm{m}$

rDNA signals were detected in the middle of the two telocentric chromosomes (5) (Fig. 2). In some preparations, minor $35 \mathrm{~S}$ rDNA sites were observed in these chromosomes (Fig. 3c, d).

Telomeric signals were revealed at the ends of all P. echinatum chromosomes (Fig. 3b). Furthermore, interstitially located TTTAGGG repeats were detected in the first three chromosome pairs: in centromeric regions of chromosomes 1 and 2 and within the secondary constriction of satellite chromosomes (3) (Fig. 3a, b). The signals within the secondary constrictions of satellite chromosomes were much bigger than these at the chromosome ends. Telomeric sequences in these sites co-occur with 35S rDNA (Fig. 3d). Interestingly, nucleolar organizer regions (NORs) enriched with these two sequences were most fragile in the karyotype, and during prophase and early metaphase, they were usually strongly decondensed (data not shown). The location of all the analyzed sequences and the fragile sites in P. echinatum chromosomes are presented in Fig. 4.

\section{Discussion}

Changes in basic chromosome numbers played an important role in the evolution of grasses (Kellogg 1998; Salse et al. 2009; Devos 2010). The most reduced chromosome number

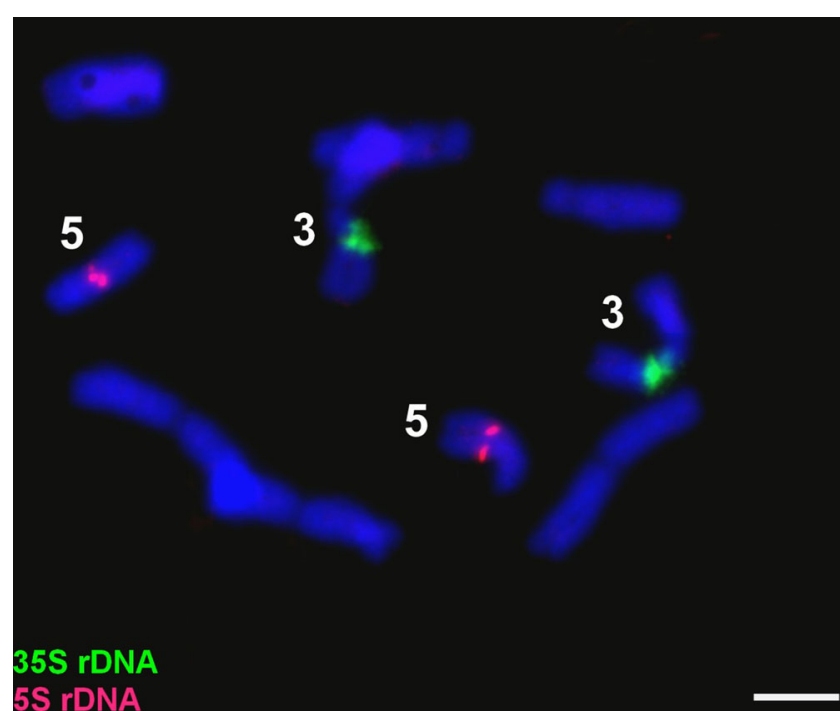

Fig. 2 Double FISH with rDNA probes on P. echinatum metaphase chromosomes: $35 \mathrm{~S}$ rDNA (green signals) in satellite chromosomes (3) and 5S rDNA (red signals) in telocentric chromosomes (5). Bar, $5 \mu \mathrm{m}$

in this group of plants $(2 n=2 x=4)$ occurs in Zingeria biebersteiniana and Colpodium versicolor (Bennett et al. 1995; Kim et al. 2009; Ruffini Castiglione and Cremonini 2012). Most probably, the direct ancestor of both species, just like the ancestor of $P$. echinatum, had the basic chromosome number $x=7$ ( $p=7$ according to Peruzzi 2013). Our research
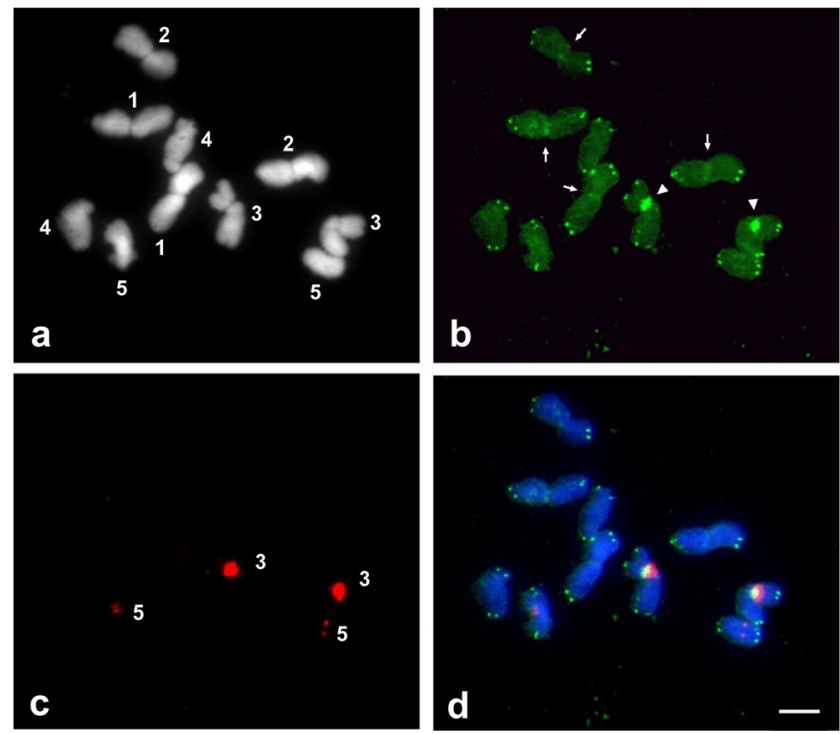

Fig. 3 FISH mapping of telomeric $\left(\mathrm{T}_{3} \mathrm{AG}_{3}\right)$ and $35 \mathrm{~S}$ rDNA sequences to metaphase chromosomes of $P$. echinatum. a The DAPI-stained and numbered chromosomes. b FISH signals of telomeric repeats. Arrowheads point to the massive accumulation of interstitial telomeric sequences (ITRs) within the secondary constriction of satellite chromosomes (3). Arrows point to telomeric signals located at the centromeric regions of chromosomes 1 and 2. $\mathbf{c}$ FISH signals of 35S rDNA sequences located within satellite chromosomes (3) and telocentric chromosomes (5). d Double FISH with 35S rDNA (red) and telomeric (green) probes; Note the co-occurrence of telomeric repeats and 35S rDNA within the secondary constriction of satellite chromosomes (3). Bar, $5 \mu \mathrm{m}$ 


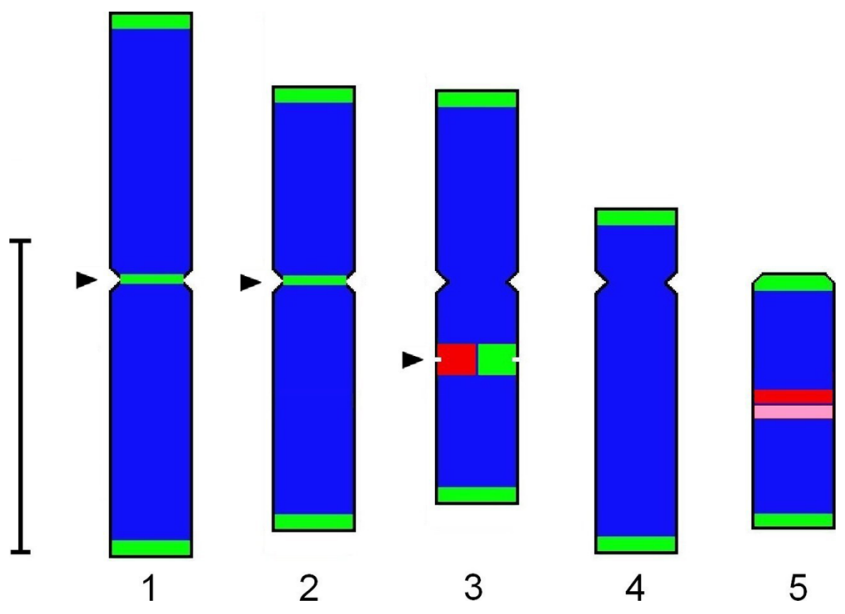

Fig. 4 Idiogram of $P$. echinatum chromosomes with hybridization sites indicated: telomeric sequences (green), 35S rDNA (red) and 5S rDNA (pink). Arrowheads point to the fragile sites. Bar, $5 \mu \mathrm{m}$

has confirmed the earlier data concerning both the number and morphology of chromosomes in P. echinatum (Ellestrom and Tijo 1950; Kula 2005). Moreover, it has revealed that apart from the secondary constriction in satellite chromosome, $35 \mathrm{~S}$ rDNA may occur in this species also in the central part of the shortest telocentric chromosome.

The occurrence of fragile sites in the three largest chromosomes seems the most interesting feature of the P. echinatum karyotype. They all contain intrachromosomal telomeric sequences in sites preferential for heterochromatin. It is well known that both centromeric regions and NORs are domains enriched with heterochromatin (Joachimiak et al. 1997; Guerra 2000; Amor et al. 2004; Henikoff and Dalal 2005). According to Ruiz-Herrera et al. (2008), heterochromatic intrachromosomal telomeric repeats (het-ITRs) are particularly prone to breakage in mammalian genomes.

In the secondary constriction of chromosome 3 , the most fragile site, $35 \mathrm{~S}$ rDNA is accompanied by telomeric repeats. The NOR regions were found to exhibit fragility and mobility in many plant species (Thomas et al. 2001; Huang et al. 2008; Raskina et al. 2008). It could be linked with the mobility of rDNA per se or the activity of the transposable elements located near or within rDNA clusters (Schubert and Wobus 1985; Gernand et al. 2007; Raskina et al. 2008). The cooccurrence of rDNA and telomeric repeats in the secondary constriction of chromosome 3 in P. echinatum might be an extra factor destabilizing this site.

In mammalian genomes, the length of interstitial telomeric sequences (ITRs) (and other microsatellite repeats) is one of the factors leading to genome instability (Lin and Yan 2008). It has been suggested that from many ITRs, only large blocks of telomeric repeats (spanning several hundred $\mathrm{kb}$ ) are involved in chromosome breakage, whereas instability of short ITRs is more controversial (Lin and Yan 2008; Ruiz-Herrera et al. 2008). ITRs observed in P. echinatum definitely contain a high number of repeats because FISH performed on condensed chromosomes cannot detect target loci smaller than $10 \mathrm{~kb}$. It is worth mentioning that the most fragile site in the P. echinatum karyotype was also characterized by the largest accumulation of telomeric repeats.

As far as the origin is concerned, ITRs in P. echinatum are most probably remnants of evolutionary chromosomal fusions which led to the reduction in chromosome number in this species. The large size of the three chromosomes in which they occur also suggests that they could have been shaped this way. The secondary constriction of chromosome 3 , where telomeric sequences are located near $35 \mathrm{~S}$ rDNA, seems particularly interesting. According to Raskina et al. (2008), the occurrence of interstitially located 35S rDNA clusters and traces of telomeric sequences inside $35 \mathrm{~S}$ rDNA is unquestionable indicators of chromosome rearrangements. Telomeric sequences in this place could be traces of chromosome healing provoked by earlier breaks within rDNA. It is well known that double-stranded breaks provide templates for new telomeres (Bolzan and Bianchi 2006). Later, chromosome fragments containing rDNA, ended with telomeres formed in this way, might have been subject to a fusion, creating chromosome 3 of $P$. echinatum within which further amplification of telomeric sequences may have taken place. It has been suggested that ITRs resulting from fusion can undergo amplification through various mechanisms (unequal crossing over, replication slippage, conversion-like mechanisms, and rolling circle replication) (Lin and Yan 2008). The other ITRs of P. echinatum were located in the regions of centromeres of chromosomes 1 and 2. Large, similarly located sequences of telomeric origin were found in the karyotype of the potato (Tek and Jiang 2004). According to the authors, there are traces of earlier chromosome fusions.

Our study has fully confirmed the supposition that the $P$. echinatum karyotype is a product of dysploid reduction caused by complex chromosome rearrangements followed by the loss of centromeres. These changes were accompanied by massive amplification of some sequences, which led to doubling the DNA amount in the basal genome of this species. It is interesting because the genus Phleum is known to have small genome among Pooideae, which is close to the estimated ancestral 1.3 pg (Kellogg and Bennetzen 2004). The research conducted has shown so far that the increases in basic genome size occur predominantly by episodic transposon bursts, often associated with chromosome rearrangements or provoked by hybridity (Lonnig and Saedler 2002; Bennetzen 2005).

The closest diploid relatives of $P$. echinatum (belonging to the Phleum alpinum group) are perennial taxa with mediumsized chromosomes, symmetric karyotype and small genome size (Joachimiak and Kula 1996; Joachimiak 2005; Stewart et al. 2011). The stomata of $P$. echinatum $(\sim 46 \mu \mathrm{m})$ are bigger than those in di- and even tetrapoid representatives of 
P. alpinum group (Kula 2005) and in hexaploid Phleum pratense (Joachimiak and Grabowska-Joachimiak 2000). Watanabe et al. (1999) suggested that the reduction in chromosome number, increase in mean chromosome length and karyotype asymmetry are correlated in plants with the change in habit from perennial to annual. According to these authors, lowering of chromosome number results in a reduction of total chromosome length (genome size) and cell size, which favours shortening of cell cycle in annuals. P. echinatum is characterized by annual habit and significantly increased genome and cell size, then it does not fit this pattern. This may suggest the involvement of other factors (e.g. hybridity) in the origin of this species. More detailed explanation of evolutionary processes which shaped its chromosomes requires further research.

Acknowledgments The authors wish to express their gratitude to Dr. Giuseppe Certa from The Botanical Gardens of Palermo for providing comparative herbarium material of Phleum echinatum Host.

Conflict of interest The authors declare that they have no conflict of interest.

Open Access This article is distributed under the terms of the Creative Commons Attribution License which permits any use, distribution, and reproduction in any medium, provided the original author(s) and the source are credited.

\section{References}

Amor DJ, Kalistis P, Sumer H, Choo KHA (2004) Building the centromere: from foundation proteins to 3D organization. Trends Cell Biol 14:359-368. doi:10.1016/j.tcb.2004.05.009

Bennett ST, Leitch IJ, Bennett MD (1995) Chromosome identification and mapping in the grass Zingeria biebersteiniana $(2 \mathrm{n}=4)$ using fluorochromes. Chromosome Res 3:101-108. doi:10.1007/ BF00710670

Bennetzen JL (2005) Transposable elements, gene creation and genome rearrangement in flowering plants. Curr Opin Genet Dev 15:621627. doi:10.1016/j.gde.2005.09.010

Bolzan AD, Bianchi MS (2006) Telomeres, interstitial telomeric repeat sequences, and chromosome aberrations. Mutat Res 612:189-214. doi:10.1016/j.mrrev.2005.12.003

Campell BR, Song Y, Posch TE, Cullis CA, Town CD (1992) Sequence and organization of $5 \mathrm{~S}$ ribosomal RNA-encoding genes of Arabidopsis thaliana. Gene 112:225-228. doi:10.1016/03781119(92)90380-8

Casper A, Nghiem P, Arlt MF, Glover TW (2002) ATR regulates fragile site stability. Cell 111:779-789

Devos KM (2010) Grass genome organization and evolution. Curr Opin Plant Biol 13:139-145. doi:10.1016/j.pbi.2009.12.005

Ellestrom S, Tijo JH (1950) Note on the chromosomes of Phleum echinatum. Bot Notiser 4:463-465

Gernand D, Golczyk H, Rutten T, Ilnicki T, Houben A, Joachimiak AJ (2007) Tissue culture triggers chromosome alterations, amplification and transposition of repeat sequences in Allium fistulosum. Genome 50:435-442. doi:10.1139/G07-023

Guerra M (2000) Patterns of heterochromatin distribution in plant chromosomes. Genet Mol Biol 23:1029-1041. doi:10.1590/S141547572000000400049

Hellman A, Zlotorynski E, Scherer SW, Cheung J, Vincent JB, Smith DI, Trakhtenbrot L, Kerem B (2002) A role for common fragile site induction in amplification of human oncogenes. Cancer Cell 1:89 97. doi:10.1016/S1535-6108(02)00017-X

Henikoff S, Dalal Y (2005) Centromeric chromatin: what makes it unique? Curr Opin Genet Dev 15:177-184. doi:10.1016/j.gde. 2005.01.004

Houben A, Field BL, Saunders V (2001) Microdissection and chromosome painting of plant B chromosomes. Methods Cell Sci 23:115124. doi:10.1023/A:1013178623270

Huang J, Ma L, Yang F, S-z F, Li L (2008) 45S rDNA regions are chromosome fragile sites expressed as gaps in vitro on metaphase chromosomes of root-tip meristematic cells in Lolium spp. PLoS One 3:e2167. doi:10.1371/journal.pone.0002167

Huang J, Ma L, Sundararajan S, S-z F, Li L (2009) Visualization by atomic force microscopy and FISH of the $45 \mathrm{~S}$ rDNA gaps in mitotic chromosomes of Lolium perenne. Protoplasma 236:59-65. doi:10. 1007/s00709-009-0051-x

Ijdo JW, Wells RA, Baldini A, Reeders ST (1991) Improved telomere detection using a telomere probe (TTAGGG)n generated by PCR. Nucleic Acids Res 19:4780

Joachimiak A (2005) Heterochromatin and microevolution in Phleum. In: Sharma AK, Sharma A (ed) Plant genome: biodiversity and evolution, vol. 1, Part B: Phanerogams. Science Publishers Inc., Enfield (NH), USA, Plymouth, UK. pp. 89-117

Joachimiak A, Grabowska-Joachimiak A (2000) Stomatal cell length and ploidy level in four taxa belonging to the Phleum sect. Phleum. Acta Biol Cracov Ser Bot 42:103-107

Joachimiak A, Kula A (1993) Cyto-taxonomy and karyotype evolution in Phleum sect. Phleum (Poaceae) in Poland. Plant Syst Evol 188:1730. doi:10.1007/BF00937833

Joachimiak A, Kula A (1996) Karyosystematics of the Phleum alpinum polyploid complex (Poaceae). Plant Syst Evol 203:11-25. doi:10. 1007/BF00985234

Joachimiak A, Kula A, Grabowska-Joachimiak A (1997) On heterochromatin in karyosystematic studies. Acta Biol Cracov Ser Bot 39:6977

Kaufmann WE, Reiss AL (1999) Molecular and cellular genetics of fragile X syndrome. Am J Med Genet 88:11-24. PMID:10050961

Kellogg E (1998) Relationships of cereal crops and other grasses. Proc Natl Acad Sci U S A 95:2005-2010. PMID: 9482825

Kellogg E, Bennetzen JL (2004) The evolution of nuclear genome structure in seed plants. Am J Bot 91:1709-1725. doi:10.3732/ajb. 91.10.1709

Kim ES, Bolsheva NL, Samatadze TE, Nocov NN, Nosova IV, Zelenin AV, Punina EO, Muravenko OV, Rodionov AV (2009) The unique genome of two-chromosome grasses Zingeria and Colpodium, its origin, and evolution. Russ J Genet 45:1329-1337. doi:10.1134/ S1022795409110076

Kula A (2005) Karyology and morphology of species from the genus Phleum. [in Polish]. Zesz Nauk Akad Rol wKrakowie 418(304):1171

Lin KW, Yan J (2008) Endings in the middle: current knowledge of interstitial telomeric repeats. Mutat Res 658:95-110

Lonnig W-E, Saedler H (2002) Chromosome rearrangements and transposable elements. Annu Rev Genet 36:389-410. doi:10.1146/ annurev.genet.36.040202.092802

Marciniuk P, Musiał K, Joachimiak AJ, Marciniuk J, Oklejewicz K, Wolanin M (2012) Taraxacum zajacii (Asteraceae) a new species from Poland. Ann Bot Fenn 49:387-390. doi:10. $5735 / 085.049 .0611$ 
Peruzzi L (2013) " $x$ " is not a bias, but a number with real biological significance. Plant Biosyst 147:1238-1241. doi:10.1080/11263504. 2013.86.1533

Raskina O, Barber JC, Nevo E, Belyayev A (2008) Repetitive DNA and chromosomal rearrangements: speciation-related events in plant genomes. Cytogenet Genome Res 120:351-357. doi:10.1159/000121084

Ruffini Castiglione M, Cremonini R (2012) A fascinating island: $2 \mathrm{n}=4$. Plant Biosyst 146:711-726. doi:10.1080/11263504.2012.714806

Ruiz-Herrera A, Ponsà M, García F, Egozcue J, García M (2002) Fragile sites in human and Macaca fascicularis chromosomes are breakpoints in chromosome evolution. Chromosome Res 10:3344. doi:10.1023/A:1014261909613

Ruiz-Herrera A, Negradze SG, Santagostino M, Giulotto E (2008) Telomeric repeats far from the ends: mechanisms of origin and role in evolution. Cytogenet Genome Res 122:219-228. doi:10.1159/ 000167807

Salse J, Abrouk M, Bolot S, Guilhot N, Courcelle E, Faraut T, Waugh R, Close TJ, Messing J, Feuillet C (2009) Reconstruction of monocotyledoneous proto-chromosomes reveals faster evolution in plants than in animals. Proc Natl Acad Sci U S A 106:14908-14913. doi:10.1073/pnas.0902350106

Schubert I, Wobus U (1985) In situ hybridization confirms jumping nucleolus organizing regions in Allium. Chromosoma 92:143-148. doi:10.1007/BF00328466

Sliwinska E, Kula A, Joachimiak A, Stewart AV (2003) Genome size in seven Phleum species. In: International workshop on application of novel cytogenetic and molecular techniques in genetics and breeding of grasses, Poznań, Poland, 1-2 April 2003. p.19

Stewart AV, Joachimiak A, Ellison N (2009) Genomic and geographic origins of Timothy (Phleum sp.) based on ITS and chloroplast sequences. In: Yamada T, Spangerberg G (ed) Molecular breeding of forage and turf. Springer, pp. 71-81

Stewart AV, Joachimiak AJ, Ellison NW (2011) Phleum. In: Kole C (ed) Wild crop relatives: genomic and breeding resources. Millets and grasses. Springer, pp. 257-274

Tek AL, Jiang J (2004) The centromeric regions of potato chromosomes contain megabase-sized tandem arrays of telomere-similar sequence. Chromosoma 113:77-83. doi:10.1007/s00412-004-0297-1

Thomas HM, Harper JA, Morgan WG (2001) Gross chromosome rearrangements are occurring in an accession of the grass Lolium rigidum. Chromosome Res 9:585-590. doi:10.1023/ A:1012499303514

Toledo F, Coquelle A, Svetlova E, Debatisse M (2000) Enhanced flexibility and aphidicolin-induced DNA breaks near mammalian replication origins: implications for replicon mapping and chromosome fragility. Nucleic Acids Res 28:4805-4813. doi:10.1093/nar/28.23. 4805

Watanabe K, Yahara T, Denda T, Kosuge K (1999) Chromosomal evolution in the genus Brachyscome (Asteraceae, Asterae): statistical tests regarding correlation between changes in karyotype and habit using phylogenetic information. J Plant Res 112:145-161. doi:10.1007/PL00013869 